CAHIERS

MONDES

ANCIENS

\section{Cahiers « Mondes anciens »}

Histoire et anthropologie des mondes anciens

$13 \mid 2020$

Qu'est-ce que faire école? Regards sur « l'école de

Paris »

\title{
The External Rapport on the Centre Gernet, 1996
}

L'audit du Centre Gernet en 1996

\section{Oswyn Murray}

\section{OpenEdition}

Journals

Electronic version

URL: http://journals.openedition.org/mondesanciens/2654

DOI: 10.4000/mondesanciens.2654

ISSN: 2107-0199

Publisher

UMR 8210 Anthropologie et Histoire des Mondes Antiques

Electronic reference

Oswyn Murray, «The External Rapport on the Centre Gernet, 1996 », Cahiers « Mondes anciens » [Online], 13 | 2020, Online since 10 June 2020, connection on 12 June 2020. URL : http://

journals.openedition.org/mondesanciens/2654 ; DOI : https://doi.org/10.4000/mondesanciens.2654

This text was automatically generated on 12 June 2020 .

\section{(c) (i) () $\Theta$}

Les Cahiers «Mondes Anciens » sont mis à disposition selon les termes de la licence Creative Commons Attribution - Pas d'Utilisation Commerciale - Pas de Modification 4.0 International. 


\title{
The External Rapport on the Centre Gernet, 1996
}

\author{
L'audit du Centre Gernet en 1996
}

Oswyn Murray

1 In 1996 I was asked by the EHESS and the Centre Gernet to conduct an audit of the Centre; the invitation came from Jacques Revel at the suggestion of François Hartog. It was thought that, although I had visited the Centre often, most notably in 1985 as directeur associé (and later in 2001) I was sufficiently independent to offer an unbiased account of the current workings and future prospects of the Centre from an international viewpoint. I gained the impression that there was some doubt about whether the Centre would continue to be funded by the EHESS and the CNRS after the retirement of its two great leaders Jean-Pierre Vernant and Pierre Vidal-Naquet; there was also considerable discussion about what sort of directeur might be appropriate, whether the position should continue to be regarded as a permanent one or be held successively among the active members of the Centre: this was seen as a problem because it was felt the EHESS would require that the post should be held by one of their number, and at the time the only two possibilities were Hartog and Lissarrague (who had only just been elected to the EHESS in June), and neither of them were keen to take on the job - though in the end they served successively from 1998 to 2006. Although the threats to the survival of the Centre were not perhaps as great as some of us imagined, the Centre needed to have a clear idea of where it was going.

2 I took my duties very seriously, for I had just previously served as an external adviser to the Fonds National Suisse on the future funding of humanities research in Switzerland. There I was one of two assessors in Classics (the other was Gianbiagio Conte of Pisa) alongside pairs of assessors for history, theology, etc. We had held many meetings in Basel and had visited most of the Swiss university research institutes. The problems in Switzerland were however much more serious: the Swiss have never experienced their "soixante-huit"; their professors were (and still are) nineteenth century autocrats ruling over a mutinous Mittelbauproblem, researchers who had not the slightest hope of a permanent university position and who depended entirely on 
great research projects funded by the FNS, which were never intended to come to an end, at least until the current researchers retired.

3 I was therefore very conscious of the need to consult all levels of the Centre, from the secretarial and library staff to the researchers, including those professors in the provinces who depended on the Centre for their research needs, and those young researchers beginning their doctorats. There was also a sense that the Centre in recent years had evolved from a group of like-minded researchers, into a famille perhaps too much under the control of the directeur: in the past there had been some famous quarrels which did indeed perhaps suggest it was more of a slightly fractious famille than an institution, whereas the library and photographic collection had grown to be one of the most important research tools in Paris. This development from famille to institute also brought about its own tensions, as Pierre sought to add new members to the group, sometimes against the desire of existing members.

It is difficult twenty years later to recall those distant days, before the move from rue Monsieur-le-Prince to the rue Vivienne. In the event many of these problems disappeared, not least thanks to a succession of directeurs after Pierre, from Hartog and Lissarrague onwards and the creation of the joint Gernet-Glotz library and ANHIMA. But to recall the experiences and the difficulties of those ancient days, I remember Jesper Svenbro asking me in 1985 in the corridor near the toilette (the only place for a private conversation) what I thought of the Paris libraries; despite the fact that I had a special private recommendation to be allowed access to the Ecole Normale, I replied that they were very difficult to access and to use. "Yes" replied Jesper, "that is why French scholarship is so imaginative: they can never find the books and therefore they have nothing to prevent them from thinking, and no problem with footnotes". This period of deprivation and penury had perhaps its advantages.

5 I worked systematically for a week conducting interviews with all existing and previous members of the Centre, from Vernant, Vidal-Naquet and Nicole Loraux to staff such as Nicole Sels and Viviane Therault. I was a great pleasure to be welcomed into the Centre so completely and perhaps to assist in its preservation as a major international centre of recherches comparées. Jacques Revel was certainly grateful for my report, and could use it in the discussions in the scientific council of the EHESS (where they decide which group can be sustained or left out). But my report is best read in the accompanying document, long lost but now rediscovered in the archive of ANHIMA in its original format, produced long before the existence of word programmes.

\section{Centre Louis Gernet - Audit 19-24 June 1996}

By Oswyn Murray

\section{Documentation and procedure}

\section{I.1. Documentation}

7 The quality of any evaluation depends on the quality of the response from the institution. Indeed one of the main functions of an audition must be to provoke 
discussion, self-criticism and definition of goals within the institution. In the case of this review of the Centre Gernet, the documentation was exemplary. It consisted of:

1. Three official "rapports d'activité" compiled for the CNRS, two covering the years 1990-1992 and 1992-1994, and the draft of a third in preparation for 1994-1996. These covered all aspects of organisation, membership, research and publication.

2. A document "Le Centre Louis Gernet et ses perspectives", compiled during 1996 by the members of the Centre as a result of internal discussions, precisely for the audit. This was based especially on a general consultation by questionnaire of all members of the Centre, to which some forty replies were received. This document was especially useful in representing frankly and without official implications what the members of the Centre thought about problems and priorities.

3. Published articles by J.-P. Vernant ("Chercheur au CNRS") and Nicole Loraux ("Back to the Greeks"), concerning the early ideals and the history of the Centre.

\section{I.2. Meetings}

8 During the five days I held a variety of meetings formal and informal with members of the Centre, who made every attempt to introduce me to the normal workings of the Centre by rearranging meetings to these days so that I could be present. The meetings consisted of:

1. A formal meeting of the Conseil de Laboratoire, composed of members elected from the different groups in the Centre. Most of the business was the normal business of deciding allocation of research money etc.

2. An assemblée générale of all the members of the Centre at which there was a long and frank discussion of all the problems of the Centre, of the tensions between different interests and different groups and how to resolve them.

3. A 2-hour meeting with the chercheurs of the CNRS to discuss their status within the Centre and their problems in relation with the other members of the Centre.

4. A regular research seminar given by the CNRS members of the Centre but open to the others.

5. A meeting with the young students preparing their doctorates and working in the library; this was attended by 9 students in various stages of research, from France, Italy, Switzerland, Greece and Brazil.

6. A series of 11 private interviews with members of the Centre, who represented the main interests in the Centre together with two interviews with the librarian and the secretary in charge of the accounts.

7. Many informal discussions with the Director and the Associate Directors.

8. A final meeting with the members of the Centre, at which I presented the first draft of this report, and discussed it with them. The meeting lasted almost two hours, and I modified my report to take into account of the comments made.

9 At every stage I was impressed both by the quality of the documentation and by the openness of the debates in relation to the strengths and problems of the institution. I was welcomed into a group, and felt myself part of a process of self-criticism which will surely continue, and which was one of the most remarkable aspects of a dynamic and democratic institution. My general impression of both research and organisation was extremely positive in relation with to the other institutions of which I have been a member or which I have studied. 


\section{3. Function and qualification of Auditor}

10 I took my function to be assessing the scientific work of the Centre, acting as a provoker of discussion in relation to the audit and the future of the Centre, and approving or offering ideas for the better organisation of the Centre. It is in the nature of such an exercise that many of the suggestions made merely confirm what members of the Centre have already proposed; while some are addressed externally to the CNRS and the EHESS, others concern internal matters and are addressed to members of the Centre itself.

11 The qualifications of the auditor may add weight to the suggestions made. I am Fellow of Balliol College and University Lecturer in Ancient History at Oxford. I am independent of the Centre, though I work in the same field of some of its members and have long admired its work; my informal association goes back to the seventies, when I first met J.-P. Vernant and especially P. Vidal-Naquet, during his visit to Oxford; I was professeur associé at the EHESS attached to the Centre in 1985.

12 My administrative experience concerns especially the working of small institutions; I have been a Research Fellow at the Warburg Institute, London, and was subsequently for more than a decade a member of its Management Committee; and I have held successive posts as Senior Tutor and Vice-Master for almost ten years in my College. In 1996 I was invited by the Conseil Suisse de la Science to take part in a commission of 10 experts to study the entire field of research in Geistwissenchaft in all the Universities of Switzerland; the visit and report have just been completed.

\section{The Centre Louis Gernet de recherches comparées sur les sociétés anciennes}

\section{1. Historical considerations}

13 The Centre originates in a informal group around the figure of Jean-Pierre Vernant, united by friendship and common research interests; five existing members belong to this period of the initial seminar of Vernant. Through the generosity of the EHESS (to which it became attached) it acquired its present accommodation and was able to build up a library. In the early seventies a second generation of researchers was attached, deriving from members of the seminars of Vernant, Vidal-Naquet and Detienne, and later of Nicole Loraux; this group comprises some 16 active members of the Centre. A third group of some 9 members arrived in the late seventies, at which time the Centre became officially a place of attachment for chercheurs of the CNRS. There have been a few additions in the nineties of former students connected with the Centre who obtained university posts, and especially of experts in other ancient societies welcomed because of the comparatist aims of the Centre. Recently the recruitment of new members has slowed down, and the majority of members fall into two age groups centred on the ages of 50 and 40+; this imbalance and the lack of younger members has caused some anxiety.

\section{2. The present situation}

14 At present the Centre contains some fifty active members together with an administrative staff of one librarian and two technicians. The members are of three 
different 'generations'; but more importantly they are of different types and different needs. The main groups are:

- Directeurs d'études and maittres de conférence of the EHESS formally attached to the Centre (3 à titre principal, 3 à titre secondaire).

- Chercheurs CNRS (9). They have recently instituted their own research seminar within the Centre, and (with group 1) represent the most active members of the Centre on a day-to-day basis.

- Enseignants at the École Pratique des Hautes Etudes ( $\mathrm{V}^{\mathrm{e}}$ section) and in the Universities of Paris (numbers vary) who are also present almost on a daily basis.

- Enseignants in the 'universités de province' who come with more or less frequency according to their duties and place oh habitation.

There are two further groups whose needs should be considered:

- Students for the Doctorate introduced by members of the Centre and working often for several years using the library and other facilities of the Centre as their main focus.

- Occasional visitors from overseas and France introduced or invited by members of the Centre.

16 The existence of all these varied groups with more or less institutional or moral rights to have their needs considered is one main focus of this report.

\section{3. The quality of Research}

The reputation of the Centre Louis Gernet is worldwide. Beginning with the production of a charismatic leadership (J.-P. Vernant, P. Vidal-Naquet, M. Detienne), its members are generally regarded as the most productive and most interesting group of scholars working in ancient social and cultural history in France, and perhaps in the world. It would be invidious to single out the works of individual authors of what is sometimes referred to as the École de Paris; but I may perhaps list some of the main areas in which the group has been active: it began with studies of Greek myth, Greek tragedy, Greek social forms, suppressed groups (slaves, foreigners, women) and comparative studies of themes such as war, the land, and sacrifice. There are distinguished contributions to Roman religious and social history, and to the study of China, the ancient Near East and Iran. Perhaps the most important new direction in work in the Centre in recent years has been the development of a group of experts in the iconography of Greek vasepainting in its relation to social structures and mental forms, with an associated photothèque: this has in turn informed the writing of many other members of the group and given it a distinctive comparative methodology. The research activity is not confined to those with posts at the CNRS; those with university posts are also very active. The journal Métis is associated with the Centre; it is of an excellent standard and is widely distributed.

The Centre has established a reputation as the most prestigious group of researchers working in France in Greek history; to outsiders sometimes it seems as if the Centre is Greek history in France: this obviously does injustice to the many individual talented scholars working elsewhere; but it does express the correct feeling that in Greek history this is the most important group in France. As a consequence there is a constant flow of foreign visitors, and the Centre has become the interface between French and international scholarship: this results in a high degree of invitations and visiting 
professorships for members of the Centre, as well as being a means for disseminating their ideas through lectures and translations of their books.

The proposals for future research are listed in the rapports for the CNRS, and were the subject of a lively discussion in the assemblée générale at which I was present. It is clear that the future holds as much promise as the past. On the other hand the very success of the Centre, its high prestige, and the size and variety of its body of researchers pose problems of organisation which are discussed below.

\section{Problems and suggestions for improvement}

\section{1. General Problems}

One of the factors behind the varied difficulties facing the Centre is the problem of agreeing change in a situation where there are two separate and roughly equal sources of funding, the EHESS and the CNRS; there is a tendency for each funding body to regard itself as not responsible for a particular aspect, or to treat requests for funding according to rules which are simply not appropriate. In order to point up this difficulty, I list tree aspects where neither body seems at present to take effective responsibility for essential functions:

- It seems to me incredible that the CNRS concerns itself so little with the provision of offices in which its researchers can work, thereby compelling them to work at home for much of the time.

- It also seems to me incredible that neither the CNRS nor the EHESS apparently believes that it is its responsibility to provide for their researchers both individual computing equipment and the essential backup in terms of technical staff. In other countries these are considered basic duties of employers of research staff.

- It seems to me a contradiction that the Centre is given money to buy books on condition that it opens its facilities to a wider group; and that it is then told that it is overprovided with technical staff in terms of the number of its chercheurs for the CNRS, and that it may therefore lose the essential post of librarian when the present holder retires.

It is easy to say that a foreigner does not understand the system, and that these instances are part of a wider set of problems; but when the system throws up such obvious anomalies, it is perhaps time to look beyond the Centre to the functioning of its parent bodies.

\section{2. Space}

The Centre has four small administrative offices, two for the secretarial staff, one used mostly for library work, and one for the Director and for any private meeting needed for the reception of visitors. There are a series of rooms which act as passages, a windowless cubbyhole for the librarian, and a single reading room which doubles as meeting place, seminar room and social space. Recently a subterranean bookstore and reading space has been added; but this can be reached only through the upper room, and is therefore inaccessible during meetings. On a separate floor upstairs there is a very attractive small office (currently used for storage and as an office for the journal Métis), and a good-sized computer room.

It is evident to any visitor that part of the charm of the Centre and its ability to function as a meeting place and lively forum for the exchange of ideas is that no-one 
(not even the Director) has any private space, indeed often no place even to sit down. On the other hand this is clearly not an ideal situation for research, however collaborative.

Leaving aside any radical suggestions such as moving the Centre to a larger and less central location (which would have serious consequences in terms of its relation to other places of work and other complementary libraries), it is possible to suggest some modifications. The space on the first floor could be better used: for instance, if the computing equipment were rearranged, space could be made for a small working room for the chercheurs of the CNRS. The office next door could be used more effectively.

There remain fundamental problems in relation to the multiple use of the library, the absence of individual or shared offices for the chercheurs, and the fact that (even with rolling stacks in the basement) the library has space only for a further five years of books. If space should become available elsewhere in the building, I would regard it as a high priority that the Centre is found a room for seminars and meetings, and some additional offices for chercheurs.

\section{3. The Library}

The library is an outstanding specialised library of some 15, 000 volumes, increasing by about 550 a year; it has been created and maintained by the members of the Centre and reflects their interests. During the last few years a full-time librarian has been employed: she has transformed the organisation of the library and introduced a computer catalogue with search facilities linked to the programme FRANTIQ. CDRom facilities are available for the Thesaurus Linguae Graecae, and for DYABOLO (a bibliographical database created by the German Institute in Rome); a database of images is in progress.

The library has a number of obvious drawbacks. Is is often full: there are only 14 seats for readers inclusive of those in the basement. It is closed in the afternoons whenever meetings and seminars are held. On grounds of space and expense the decision has been made in general only to acquire 11 periodicals (a few periodical runs have come as gifts, but they are not continued). This is a serious disadvantage in a research library, and I feel that the policy ought to be kept under review. It should be possible to limit the expense by using Métis for exchange (the Warburg Institute in London acquires many of its foreign periodicals through such exchanges), and by buying only those journals which are not easily accessible elsewhere. The use of an external depot (see below) might alleviate space problems.

The limitation of library purchases to the areas of classical texts, Greek social and cultural history and Greek iconography might seem to be a serious problem, especially given the declared function of the Centre as a centre de recherches comparées. I received various suggestions that this served to marginalise recherches comparées in general, and Roman and Near Eastern studies in particular. Others working in these fields felt that the policy was justified in the light of facilities available in nearby libraries such as that of the Centre Glotz for Roman history, the École Pratique, the Sorbonne and the Ecole Normale. I agree with this latter view: the budget and the space available necessarily require limitation of subject area; and Roman studies in particular are well served elsewhere. However if there is no other library for a particular group of researchers in 
their subject area, the the Centre might be faced with making a policy decision either to provide library resources or to abandon research in that area.

Research library provision in Paris is not as good as in many major European cities, and the system clearly requires some years of practice by the individual researcher before he can find the best places to work. In this respect a computer union catalogue (such as now exists for all the foreign schools in Rome) devoted to a wider subject area such as classical studies would be a great step forward. This might be undertaken by a group of research libraries such as the Centre and the Centre Glotz, and might be seen as a cheaper alternative to the creation of a united library proposed some years ago; for such a capital computing project might not central funds be made available?

There is an acute problem with space in the library; it needs a dedicated reading room, and in five years time the space for books will run out. The first question is a priority; the second might be met by the expedient of establishing a depot elsewhere, probably in concert with other libraries with the same problem.

31 The students complained about the opening hour over lunch and in the early evening. Two possibilities might be considered. The students might be more involved in the servicing of the library (possibly without payment as a return for the privilege of using the library) with a rota of invigilation. And in the evenings the system that is in operation at the Warburg Institute might be applied. There each day a notice is posted giving the time at which the last member of academic staff will leave; readers are allowed to stay until that point, though they are not permitted to enter after closing hours.

To summarise I recommend:

- The replacement of the present librarian when she retires is essential.

- There should be high priority for finding a seminar room separate from the library.

- The present subject limitations should be maintained but reviewed from time to time. It should be clearly recognised that an invitation to a researcher to become member of the Centre may involve an initial capital sum and recurrent expenditure for the provision of essential books in a new area; and this should be discussed at the time a proposal for membership is made.

- The present policy of acquiring very few periodicals should be kept under review to see wether new titles might not be added.

- The Centre should explore the possibility of creating a joint computer catalogue with other nearby libraries in order to extend its coverage.

- Consideration should be given to extending the opening hours, by the use of student helpers over lunch, and by accepting that readers should be allowed to stay in the evening until the last permanent member leaves.

- The Centre should explore the possibility of a depot (perhaps at the Ecole Normale, perhaps jointly with other libraries) for seldom consulted books, with a view to establishing a 'steady state' library.

- The Centre should continue to expand its holdings in computer databases as a supplement to the library holdings in books; one obvious need is the database of the Beazley Archive in Oxford. 


\section{4. Research}

It is in the area of research that the Centre finds itself most clearly a victim pf its own success and its own philosophy. The Centre is such an attractive and intellectually stimulating place to work that few leave it, and there is always a problem of balancing new recruitment against the numbers already attached to the Centre. The philosophy of openness and comparativism makes it difficult to view but the most conventional academic research as outside the interests of the Centre. The result is that the numbers belonging to the Centre and the diversity of their research interests can lead to fragmentation of the intellectual programme and treating the Centre merely as a library, social centre and place of work. There is not much harm in this, as long as it is balanced by an articulated research programme and common views on methodology.

The two 'secessions' in the history of the Centre, of Marcel Detienne and Nicole Loraux (in the eighties and early nineties), however painful in personal terms, were in intellectual terms positive signs of the existence of a group dynamic, and of the ability of members to leave to found their own groups when they no longer shared the same basic approaches. The absence of subsequent movement is not necessarily a good sign; it may indicate a philosophy which is too inclusive or an environment which is too attractive socially. If members of the Centre wish to leave, or (less radically) if they wish to share their allegiances with other groups or to found their own, I would regard that as a sign of continuing dynamism; above all the tensions within the Centre should not be internalised to the extent that they might threaten the existence of a common philosophy.

For such reasons it seems to me important to seek to define more clearly what now constitutes the philosophy of the Centre, and how to express it in terms of a concrete and practical programme of research. The future of the Centre as a centre of research should, it be determined by its history or by the personal friendships which have been formed over time. This process of self-definition must result from continuing discussions within the Centre; I offer some very general observations from an external point of view.

It seems to me that the declared purpose of the Centre as devoted to recherches comparées covers two separate types of research which have become somewhat confused over time.

The first type of research is comparative research between different cultures; this can be pursued either within a context which assumes equality between societies, or by centring attention on one particular society and comparing it with others. The Centre has been active in both these types of research, but it has never found a means to institutionalise them effectively. It was from early on and remains closely impossible to equalise the number of researchers across all ancient societies, or to provide them with an adequate library; there has however been a continuing and admirable attempt to broaden the cultures and disciplines represented away from ancient Greece (and Rome) by attracting individual researchers in fields such as ancient China, anthropology, modern Greece and Iran. I do not wish to underestimate the importance of continuing the tradition of such comparativism; but I would emphasise that it depends very much on the interests of the individual scholars involved. Often institutionalising such efforts falsifies the nature of the the joint enterprise, which may be more temporary, and may be better served by intercultural seminars in a wider group such as the $\mathrm{V}^{\mathrm{e}}$ section of the 
École Pratique. The Centre has had some successes here, but hey have been dependent on individual interests and the formulation of suitable specific themes.

There is a second form of comparativism which seems to me to characterise all the work of the Centre, and to encapsulate its basic philosophy as it has developed over the years. The Centre is above all a centre of interdisciplinarity: the themes and research that have come out of the Centre are essentially interdisciplinary, wether that means crossing the boundaries within and between cultures, or (more often) crossing the boundaries within a single culture between subject disciplines: contrarily the one type of research which is obviously better placed outside the Centre is that which works within the established confines of a single discipline. This I believe is why researchers come to work at the Centre and wish to be permanently attached to it -because they are unhappy with the established historical or philological categories in their parent disciplines. There should thus be a place for all who can contribute to the common enterprise of recherches comparées sur les sociétés anciennes, regardless of their initial training: and even to think in terms of the balance between different fields such as Greek history, iconography, philosophy, Roman history, Persian studies, archaeology, is to falsify the spirit of the enterprise. The Centre can therefore remain centred on the Greek world for historical reasons, without indulging in either tokenism or exclusion in relation to other ancient societies. And it is for the individual researchers to decide wether and to what extent they wish to belong to the Centre and devote themselves to études comparées in this sense.

It was in this context that I discussed with the members why they belonged to the Centre. They all had good historical reasons why they had come to it in the first place; but the question, "why do you stay here?" clearly aroused some problems. In my view the answer should be given not just in terms of friendship, loyalty, administrative convenience, or library provision; it must also be couched in terms of adherence to a common programme of comparativism and the need to collaborate. One further important point was made in relation to comparative studies. In established disciplines the rules are fixed and the individual researcher feels able to trust his own judgment; in contrast many of those who work in the Centre do so because they feel that their work is experimental and requires testing in a laboratory of researchers. The Centre offers the opportunity for genuine exploration of new themes within a context of sympathetic fellow researchers.

\section{5. The Organisation of Research}

40 The organisation of research of this type and in an institution with so many members should attempt to mediate between the liberty of research of the individual and the need for structure and collaborative group projects. It has been claimed that some 'grands projets' recently have not excited the interest that they should have done, and that perhaps the work of the Centre is becoming too fragmented and too individualised. There is some thruth in the view that even large ideas such as the recent projects on 'le temps' and 'les animaux' may turn out to be centred on the interests of a few individuals, man may not have met a full group response within the Centre on a regular basis. On the other hand other 'grands projets' like the colloque 'public/prive' was as an event a great public success, and the activities centred on iconography and myth have continued to exist in an atmosphere of group activity. I agree with those in the Centre 
who think that more direction is needed in the aims of the Centre, and make the following suggestions merely to provoke discussion.

Perhaps 'grands thèmes' should be formulated by the group to last say four years, and to be continued longer if they prove to be fruitful. Within these 'grands thèmes' smaller groups or équipes should form for particular more limited projects -a seminar, a book, a colloque, joint research etc.; the 'grands thèmes' should also be formulated in such a way as to include the efforts of the individual researcher who wishes to work on his own, but within a context. The 'grands thèmes' would also serve to define the current activity of the Centre to the outside world and would be an invitation to collaborate. I would only insist that such themes should be defined so as to privilege interdisciplinary research.

In such a way the independence of the individual researcher could be protected alongside a process of defining more clearly the changing aims of the Centre, and encouraging collaborative research. And such a programme would also provide some criterion for participation and membership at whatever level in group activities.

\section{6. The Centre and its Organisation}

The Centre needs I believe to think more clearly about relations between the interests of the various members and collaborators, and about the facilities it offers.

I make a number of quite practical suggestions intended to satisfy some of the demands I have heard:

- There should be a continuing research seminar by members of the CNRS in the programme of the EHESS to attract students and focus more clearly the teaching activity of the Centre in its parent institution. This together with 7-8 below should be seen in the context of the 'recrutement des jeunes'.

- There should be regular working seminars primarily for members of the CNRS at the Centre, which should be open to others. This is an excellent recent initiative; but care should be taken to ensure that these activities do not polarise the distinction between chercheurs CNRS and universitaires.

- Consideration should be given by the EHESS and the CNRS to the space needs of chercheurs CNRS, and to technical support for computing. The provision of Email is an urgent priority.

- The Centre should help organise and participate in colloquies in the universités de province on the lines of the 'antennes' programme mentioned in the proposals for future activity.

- There might be (say) two regular days of internal colloques a year at the Centre directed especially at maintaining links with universitaires de province.

- The Centre should continue to seek actively to establish links with other university and research groups outside France, and should offer help to those seeking to organise such joint research projects.

- Although there is no formal obligation towards students using the Centre, there needs to be some clearer informal system of looking after them, such as already exists with the Greek students. I would suggest that it is accepted as an obligation that anyone introducing a student to the Centre is responsible for acting as their 'adviser'; and that the Director should make it one of his tasks to ensure that this happens in each case. Students were often unclear about quite basic aspects of the Centre; a document regularly revised about the history and facilities of the Centre, and the rights and 
duties of students, would clear up many confusions. There should be a social meeting of students and their advisers at the start of the academic year.

- More use might be made of students in organisational matters and in running the library/photothèque, in order to involve them in the activities of the Centre, and enable them to respond to the privileges they have been offered.

- Despite the existence of the assemblée générale and the conseil de laboratoire, much of the working of the Centre is informal, and decisions have been taken from time to time without public discussion. Although such discussion is not always appropriate, it should be held wherever possible, for instance in the recruitment of new members.

- It is essential that the members of the Centre are in agreement over the nature of the position of the next director (wether effectively permanent or genuinely cyclical), and that they are fully consulted over the appointment.

\section{Conclusion}

I found the Centre a place of important research and vital discussion about the future. But within all this discussion one thing should not be forgotten. There is a freedom of research combined with a sense of belonging at the Centre which cannot be found in many other institutions. Its members are immensely privileged in terms of their common aims, the quality of their colleagues and the freedom to pursue their goals. CNRS members sometimes lose sight of this in the small frustrations of their daily existence; university teachers are more aware of these advantages. The informal atmosphere and 'les rencontres de couloir' are an essential support to 'recherches comparées'. In the modern climate of university institutions the Centre is a rare meeting place for the two cultures which are increasingly being driven apart, to the detriment of both -the full time researchers of the CNRS and university teachers: neither side should lose sight of the fact that both are engaged in a common enterprise. This was best grasped by two members from the universities, who simply said that the Centre represented for them a refuge and a Mecca for research, which did not exist within their own universities; and one who had travelled widely in other countries and sampled the delights of Oxbridge clearly thought that the Centre was intellectually and for research the best place to be. The Centre may not compare in terms of facilities with the Institute of Advanced Studies at Princeton, the Center for Hellenic Studies at Washington, All Souls College, Oxford or the Wissenschaftkolleg in Berlin; but in terms of productivity and intellectual excitement it is superior to all of these. I have enjoyed my duties enormously, and I know where I should rather work, despite all the frustrations of French academic life. 


\section{ABSTRACTS}

The author publishes, with a short introduction to its context, the rapport he had written after the audit of the Centre Gernet he made in 1996 at a crucial moment of the its history, at the request of the EHESS.

L'auteur publie, en le resituant dans son contexte, le texte du rapport qu'il avait rendu à la suite de l'audit du Centre Gernet qu'il avait avait effectué en 1996 à un moment crucial de son histoire, à la demande de l'EHESS.

\section{INDEX}

Mots-clés: Centre Louis Gernet, histoire grecque, recherche, anthropologie

Keywords: Centre Louis Gernet, greek history, research, anthropology

\section{AUTHOR}

\section{OSWYN MURRAY}

Balliol College, Oxford University 